\title{
Surgical treatment for gastroesophageal reflux in asthmatic patient
}

\author{
Omar Eissa, ${ }^{a} M D$; Mohamed Abdel Monem, ${ }^{b} M D ;$ Nader Kotb, ${ }^{b} M D$; \\ Rafat Al Sokarry, ${ }^{c} M D ;$ Ahmed Gamal EL-Din, ${ }^{b} M D$
}

\author{
a) Departement of General Surgery, Menia University, Menia, Egypt. \\ b) Departement of General Surgery, Ain Shams University, Cairo, Egypt. \\ c) Departement of Chest, Asuit University, Asuit, Egypt.
}

\begin{abstract}
Background and aim: Gastroesophageal reflux disease (GERD) is one of the most common gastrointestinal diseases facing society today. Assosciation of bronchial asthma with GERD is a common problem, we tried to evaluate the surgical treatment (reflux surgery) and its results to choose the patients who will get benefit from reflux surgery.

Patients and methods: We report the results of surgical repair of gastroesophageal reflux in 32 asthmatic patients who underwent surgery. The severe asthma was associated with clinically evident refiux, and repair was attempted by surgical technique Nissen transabdominalgastropexy and laparoscopic fundoplication.

Results: Total cure, eight cases (25\%); marked improvement, five (15.6\%); moderate improvement, eight (25\%); no improvement, 11 (34.4\%). Cure was attained in intrinsic asthma with a predominance of nocturnal crises, associated with nocturnal tracheitis and with significant reflux, objective signs of which had appeared before the beginning of the asthma. Other results concerned asthmas complicated secondarily by GER in which it was impossible to determine whether the reflux was only a complication, without effect on the respiratory illness, or exacerbating the asthma.

Conclusions: The question of surgery in these patients should be considered with care, being reserved for cases of severe asthma, poorly controlled by antiasthmatic drugs, and complicated by a severe reflux that encompasses ulcerative esophagitis. The majority of patients in most studies seem to improve symptomatically after surgery. However, a small percentage remains unchanged or worsens. The reported studies are so disparate in their methodology that firm conclusions on the role of surgery are difficult. Further studies are needed.
\end{abstract}

Key words: Gastric, esophageal, reflux, surgery, bronchial asthma.

\section{Introduction:}

Gastroesophageal reflux (GER) is the commonest upper digestive tract disorder in the world, occurring intermittently in approximately $30-40 \%$ of the adult population. ${ }^{1}$ The increased incidence of gastroesophageal reflux (GER) in asthmatic patients has been noted by several authors. $1,3,4$ The main problem raised is to determine whether the reflux aggravates the asthma or is only a complication, with no respiratory effects. Some authors ${ }^{5,6}$ have suggested clarifying the connection through study of the effect of medical antireflux treatment on asthma. Similarly, several publications investigated the influence of surgical treatment of reflux on the asthma process. ${ }^{2,5}$ A proportion of these patients present with atypical reflux symptoms, which are thought to be caused by the reflux of stomach contents into the larynx and pharynx. It is claimed that $10 \%$ of patients presenting to an ear, nose, 
and throat (ENT) specialist have a clinical condition that might be attributed to GERD ${ }^{7}$ and that reflux is present in up to $75 \%$ of patients with refractory ENT symptoms 8 More than $80 \%$ of unselected asthmatics have evidence of abnormal GER at $\mathrm{pH}$ monitoring. ${ }^{9}$ The esophagus is the most common site for noncardiac chest pain, which can be induced by GERD. ${ }^{10}$ Several reports have indicated that up to $50 \%$ of patients with asthma have either endoscopic evidence of esophagitis or increased esophageal acid exposure on 24-hour ambulatory $\mathrm{pH}$ monitoring. ${ }^{11,12}$ This suggests that the frequency of dual pathology is higher than would be expected by serendipity alone. In addition, antireflux therapy may reduce the severity of respiratory symptoms in patients with both asthma and GERD.

Despite the ubiquitous nature of both diseases and the documented association between asthma and GERD, controversy remains regarding the value of antireflux therapy in asthma.

Current guidelines, based on data from older studies with significant limitations, recommend considering treatment for reflux disease, even without the classic symptoms, in patients with uncontrolled asthma. ${ }^{13}$

The primary defect in classical GER is lower esophageal sphincter dysfunction, whereas in extraesophageal reflux (EER), it may be the upper esophageal sphincter, which also malfunctions. ${ }^{14}$ Patients with proximal reflux report significantly worse asthma and health-related quality of life despite lack of physiologic impairment or increase in asthma symptoms. ${ }^{15}$

A non cardiac chest pain is not well defined but is also considered as an extraesophageal symptom of gastroesophageal reflux disease, although it originates most likely from the esophagus. Antireflux surgery restores the anatomy of the lower esophageal sphincter and inhibits the reflux of gastric and duodenal contents. Therefore, some studies suggest that antireflux surgery may be superior to medical therapy in controlling symptoms caused by EER. ${ }^{16}$ In classical GER, Nissen fundoplication is highly successful in controlling reflux symptoms, with a reported $90 \%$ success rate at 10 years after surgery. ${ }^{17}$ There are many reports of the results of treating EER with surgical fundoplication; ${ }^{18}$ however, the role of surgery in alleviating EER symptoms remains controversial. This is due to the fact that a cause-and-effect relationship between gastroesophageal reflux and extraesophageal symptoms is often difficult to establish.

\section{Patients and methods:}

In Menia university hospital the study group was limited to those patients operated on more than four years earlier. Of a total of 32 patients in this study, 13 were men and 19 were women (mean age 49.3 \pm 1.6 years). Asthmatic condition: 32 patients had severe chronic asthma with obstructive airways disease. 23 of these patients had chronic asthma with permanent obstructive airways, the other nine subjects had episodic, incapacitating asthma, but no permanent obstructive airways disease. The mean duration of the disease was $12.1 \pm 1$ years.

All the patients recorded signs of reflux with postural pyrosis and retrosternal pain or burning. This clinical data alone indicated the existence of GER. In all cases the classic examination was carried out; esophageal fibroscopy, barium esophagogram, manometry and PH metry. In all cases surgical intervention was preceded by a three months medical therapeutic trials, which involved taking daily metoclopramide, proton pump inhibitor and sodium alginate.

\section{Surgery and post operative follow up:}

Surgical repair was carried out between 2004 and 2007 by Nissen fundoplication either open surgery (transabdominal) or laparoscopic. This process involves the positioning of a double valve to form a cuff around the abdominal esophagus one valve posterior and one anterior, stitching both to each other along the right border of the esophagus. The bulk of the assembly normally prevents it from riding up to the hiatus and ensures a long life antireflux apparatus.

Results were evaluated by individual check-ups throughout 2009 to 2013, on 
average 4 years after surgical intervention. For the digestive system, results were judged by the persistence or disappearance of clinical reflux.

\section{Respiratory system results were evaluated by a scoring system as follows:}

* Clinical scores, based on crises frequency and the possible importance of intercritical dyspnea: $0=$ no improvement; one = moderate reduction of symptoms; two $=$ significant reduction of crises; three $=$ total disappearance of respiratory symptoms.

* Treatment scores: related to the average consumption of bronchodilator and corticosteroids drugs: $0=$ unchanged consumption; one $=$ less than 50 percent reduction; two $=$ greater than 50 percent reduction in consumption; three $=$ complete cessation of treatment.

The combined respiratory results were defined as four patients groups:

Group1: 0 score $=$ failure of surgical treatment; Group 2: 1 and 2 scores $=$ slight improvement, Group 3: 3-5 scores = marked improvement; Group 4: 6 score $=$ cure of asthma Table(1).

Failure of surgical treatment, improvement, and cure of the asthma defind the dependant variable. The possible prognostic factors were the sex, age , duration and severity of asthma, predominance of night attacks, nocturinal tracheitis, etiology of asthma, clinical signs and diagnostic criteria of GER, results of medical antireflux treatment Table(2).

\section{Results:}

\section{Pulmonary results Table(1):}

Group1 - (failures) consisted of 11 cases (34.4\%), including the surgical failure cases. In all cases asthma and drug consumption were in no way modified after surgery; nine patients from this group had chronic obstructive airways disease that persisted after surgery.

Group 2 - (moderate improvement) contained eight patients $(25 \%)$; five of eight had chronic obstructive airways disease which persisted with no improvement after surgery.
Group 3 - (marked improvement) consisted of five cases (15.6); three of them had obstructive airway diseases. Despite clinical improvement, in all cases this disorder persisted but with a noticeable improvement .

Group 4- (cure of asthma) contained eight cases $(25 \%)$. It is interesting that six of eight patients presented before surgery with chronic obstructive airway disease which totally disappeared, two of these patients were corticosteroid dependent and able to stop treatment completely.

\section{Gastroenterolgy results:}

In 30 out of 32 patients, digestive signs were completely and permanently abolished following surgical repair of reflux. In the two remaining cases, the signs reappeared during the month following surgery. How likely to benefit from surgical repair of GERD was by analyzing the clinical data from each group. Tables(2,3) summarize the main data from each of the groups.

There was a negative correlation between the age of the patient at the time of surgery and the percentage of cure of asthma $(p<0.005)$ : the younger the patient, the better the result. This relation is not linked to the duration of the disease,which in turn not related to the age of the patient.

Predominantly nocturnal attacks and/or nocturnal tracheitis were a frequent feature in those cases improved or cured by surgery. The incidence of these symptoms before surgery in groups was significantly different. The predominance of nocturinal attacks existed in only 15 cases of 24 in Groups 1,2, and 3 and seven of eight in Group (4) $(p<0.05)$.

Etiologically Group 4 (cures) is set apart by the constant absence of the allergic element. In the total study group of patients, the improvement after surgical cure (Group 4) was more significant for intrinsic asthma than for extrinsic asthmas $(p<0.05)$. Moreover, all the patients who were cured had had intrinsic asthma. No extrinsic asthma was completely cured by surgery. We observed that the obstructive airways disease, its presence or absence had no indication of the possible results of surgery. 
Table (1): Longterm effectiveness of surgical repair of reflux in asthmatic patients.

\begin{tabular}{|c|l|r|r|c|}
\hline Group & Outcome & No & $\mathbf{( \% )}$ & Score \\
\hline 1 & Failures & 11 & 34.4 & 0 \\
\hline 2 & Moderate improvement, 25-50\% & 8 & 25 & $1-2$ \\
\hline 3 & Marked improvement, 75\% & 5 & 15.6 & $3-5$ \\
\hline 4 & Cure & 8 & 25 & 6 \\
\hline
\end{tabular}

*Results are taken from 32 cases operated on more than 4 years previously.

*Improvement was judged by a method of clinical and therapeutic scoring.

Table (2): Clinical profiles of asthma classified according to results of GERD surgery, No, (\%).

\begin{tabular}{|c|c|c|c|c|}
\hline & Group 1 & Group2 & Group 3 & Group \\
\hline Kendall'sTau significance & Failure & $\begin{array}{c}\text { Moderate } \\
\text { improvement }\end{array}$ & $\begin{array}{c}\text { Marked } \\
\text { improvement }\end{array}$ & $\begin{array}{l}\text { Cure of } \\
\text { asthma }\end{array}$ \\
\hline No. & 11 & 8 & 5 & 8 \\
\hline \multicolumn{5}{|l|}{ Sex: } \\
\hline M & $6(46.1)$ & $3(23.1)$ & $2(15.4)$ & $2(15.4)$ \\
\hline $\mathrm{F}$ & $5(26.4)$ & $5(26.4)$ & $3(15.8)$ & $6(31.6)$ \\
\hline \multicolumn{5}{|l|}{ Age } \\
\hline $\mathrm{yr}<50$ & $4(25)$ & $3(18.75)$ & $4(25)$ & $5(31.25)$ \\
\hline $\mathrm{yr}>50$ & $7(43.75)$ & $5(31.25)$ & $1(6.25)$ & $3(18.75)$ \\
\hline Duration of the disease & 14.5 & 12 & 8.5 & 11.4 \\
\hline \multicolumn{5}{|l|}{ Severity } \\
\hline Episodic asthma & $2(22.2)$ & $3(33.4)$ & $2(22.2)$ & $2(22.2)$ \\
\hline Chronic athma & $9(39.1)$ & $5(21.7)$ & $3(13.7)$ & $6(26.1)$ \\
\hline \multicolumn{5}{|l|}{ Predominance of night attack } \\
\hline$+\mathrm{ve}$ & $7(31.8)$ & $5(22.7)$ & $3(18.1)$ & $7(31.8)$ \\
\hline -ve & $4(40)$ & $3(30)$ & $2(20)$ & $1(10)$ \\
\hline \multicolumn{5}{|l|}{ Nocturnal tracheitis } \\
\hline +ve & $7(31.8)$ & $5(22.7)$ & $3(18.1)$ & $7(31.8)$ \\
\hline -ve & $4(40)$ & $3(30)$ & $2(20)$ & $1(10)$ \\
\hline \multicolumn{5}{|l|}{ Etiology of asthma } \\
\hline Intrinsic & $7(29.1)$ & $6(25)$ & $3(12.5)$ & $8(36.4)$ \\
\hline Extrinsic & $4(50)$ & $2(25)$ & $2(25)$ & $0(0)$ \\
\hline
\end{tabular}


Table (3): Data on gastroesophageal reflux in patients classified according to the results of GERD surgery, No.(\%).

\begin{tabular}{|c|c|c|c|c|}
\hline & Group 1 & Group2 & Group 3 & Group \\
\hline Kendall's Tau significance & Failure & $\begin{array}{l}\text { Moderate } \\
\text { improvement }\end{array}$ & $\begin{array}{c}\text { Marked } \\
\text { improvement }\end{array}$ & $\begin{array}{l}\text { Cure of } \\
\text { Asthma }\end{array}$ \\
\hline No. & 11 & 8 & 5 & 8 \\
\hline \multicolumn{5}{|l|}{ Clinical sign of GERD } \\
\hline Appeared before asthma & 0 & 0 & 0 & 7 \\
\hline Appeared after asthma & $11(44)$ & $8(32)$ & $5(20)$ & $1(4)$ \\
\hline \multicolumn{5}{|l|}{ Diagnostic criteria of GERD } \\
\hline All positive & $4(25)$ & $3(18.75)$ & $3(18.75)$ & $6(37.5)$ \\
\hline Conflicting results & $7(43.75)$ & $5(31.25)$ & $2(12.5)$ & $2(12.5)$ \\
\hline \multicolumn{5}{|l|}{$\begin{array}{l}\text { Postoperative clinical signs of } \\
\text { GERD }\end{array}$} \\
\hline Disappear & $9(30)$ & $8(26.7)$ & $5(16.6)$ & $8(26.7)$ \\
\hline persistant & $2(100)$ & 0 & 0 & 0 \\
\hline
\end{tabular}

Most of the asthma cured by antireflux surgery was for those pertaining to patients whose digestive problems began before their respiratory signs. This was true in seven cases of eight (Group 4). In the three other groups, reflux was secondary in patients already subjected to asthma $(7 / 8)$ compared with others $(0 / 24)(p<0.0001)$. Consequently, the reflux was a possibly aggravating complication of respiratory disorder, and cure of the reflux will not result in the disappearance of the asthma. Similarly Table(3), we observed that in Group 4 the results of the four diagnostic reflux tests (barium esophagogram, esophageal fiberoscopy, manometry, and determinations) confirmed the clinical data and were all positive in 6 cases of 8 (75\%), while in the other three groups this positive concordance of the four tests was noted in only 10 out of 24 cases $(41.7 \%, p<0.01)$.

\section{Discussion:}

Whereas in most published studies, the majority of patients with GER associated bronchial asthma had some degree of symptomatic improvement after surgical fundoplication; further conclusions are difficult because there are major problems with the published literature. They thus confirm the possible interest in this surgery and make it possible to establish that there is not a simple, one-way relation between asthma and GER since, while surgical repair of reflux can abolish reflux and asthma at the same time, such surgery can also heal reflux without having any effect on asthma. This indicates that the reflux can be a complication of the asthma without necessarily aggravating it (Group 1) or, on the contrary, it may have a seriously harmful effect on the disease (Groups 3 and 4). The problem thus revolves around the possibility of predicting which is the case in each individual patient. Analytical study of our results can supply only a partial answer to the problem, not a solution. Laparoscopic Nissen fundoplication has proven safe and effective in long-term studies when performed by experienced esophageal surgeons. ${ }^{19}$

Asthma can be secondary to reflux indeed, caused by it and therefore remediable by reflux surgery (Group 4). But this is a rare 
situation, associated with intrinsic asthma, which is in general severe, and with marked GER. It appears that these cases of asthma do not present highly individual clinical features, except that they are mostly accompanied by serious nocturnal tracheitis and that the attacks are often nocturnal. However, these characteristics are not exclusive to such cases of asthma Table(2). The most important clinical feature is that the reflux symptoms appear prior to the pulmonary disease: a knowledge of the order in which the symptoms occur is therefore essential to define the situation. However, in one case of eight, it was not possible to apply this theory Table(3). In these patients GER is always an apparent, major clinical feature, and the diagnostic reflux tests all correlated positively in the majority of cases. The etiology of reflux is for the most part indeterminate. In the majority of cases (Groups 1,2, and 3 ), reflux appeared secondarily during the asthmatic disease. In turn, asthma may worsen GER. Airway restriction can lead to hyperinflation and increased negative inspiratory pleural pressure, both of which may reduce the effectiveness of the lower esophageal sphincter. In addition, the betaagonists and methylxanthines used to treat asthma may impair function of the lower esophageal sphincter and exacerbate reflux (20-22). Whatever the case, in this situation, it is obvious that treatment of reflux cannot hope to cure the respiratory disease. The crux of the problem, therefore, is to determine whether the reflux is a simple complication of the asthma and is not a causal factor of the latter, or whether it plays an exacerbating role. Clinical analysis cannot completely answer this question. At best, in our experience, one may suspect this exacerbating role in cases of long standing asthmas, with or without allergic components, or in asthmas that become worse, especially at night, for no apparent reason, and also when antiasthmatic medicaments lose their efficacy. However, when signs of GER disappear after surgery, there seems to be no explanation of why the asthma is sometimes improved and sometimes unaffected. Study of pulmonary clinical data or gastroenterologic data sheds no light on the problem. Several authors 5 have stressed the significance of the predictive value of a medical treatment trial. We have seen that the trial result was always positive when surgery was effective and always negative when surgery failed. On the other hand, the medical trial may be negative when surgery improves the asthma without it being possible to differentiate patients who will respond well from those who will not. Thus, it is not possible to base the indications for surgery on medical drug trial results. Nevertheless, when this trial fails, reflux surgery should only rarely be proposed and in particular be reserved for cases where the reflux is badly tolerated and complicated by ulcerative esophagitis.

Regarding the extrinsic or intrinsic nature of asthma, only one clear fact may be drawn from our study: surgery of the reflux in a patient suffering from extrinsic asthma cannot cure the asthma. This is normal, since such a cure cannot act in any way on the allergic element. It may, however, improve the respiratory condition of the same patient. On the other hand, in intrinsic asthma, surgical cure can abolish the asthma. It is nonetheless more common for surgical intervention to result in partial improvement.

In both cases, failure is always possible. The mechanism by which the reflux acts on the tracheobronchial tree is still not fully understood. Several authors ${ }^{23}$ have suggested that aspiration of gastric contents may take place. As this occurs when in a recumbent position, it would explain the nocturnal incidence of crises in asthmatic patients with reflux. Esophageal scintiscanning makes it possible to study this mechanism, rarely present in adults. ${ }^{24} \mathrm{~A}$ more likely cause would seem to be the esophagobronchial vagal reflex, demonstrated by Mansfield and colleagues; ${ }^{25}$ however, this reflex can only lead to bronchoconstriction in cases where a state of bronchial hyperreactivity exists. ${ }^{26}$ If the vagal reflex is the cause of refluxinduced bronchoconstriction, practice of the acid perfusion test perfected by Bernstein and Baker $^{27}$ should prove highly interesting, 
since the occurrence of bronchoconstriction following perfusion bears witness to the noxious nature of acid reflux. ${ }^{23}$

However, even when resting values of ventilatory function remained unchanged following acid instillation, the bronchial responsiveness to stimuli such as methacoline and cold air increased. ${ }^{28}$ Nevertheless, we do not yet know if the asthmatic patients likely to be improved by reflux surgery are those for which the acid perfusion test is positive. Further studies are necessary to clarify this problem, all the more critical since at present we have no objective criterion by which to classify indications for surgery.

\section{Conclusion:}

Studying our surgical results and the relation between asthma and gastroesophageal reflux enables us to identify those asthmas provoked by reflux and likely to be cured by surgery. Most frequently, GER develops secondarily, and it is not possible to distinguish those refluxes which exacerbate the asthma and are therefore possibly amenable to surgery. It is for this reason that recourse to such surgery should be made with great care.

\section{References:}

1- Rakita S, Villadolid D, Thomas A, Bloomstan, Albrinck M, Goldin S: Laparoscopic Nissen fundoplication offers high patient satisfaction with relief of extraoesophageal symptoms of gastrooesophageal reflux disease. Am Surg 2006; 72: 207-212.

2- Overholdt RH, Woorhes RI: Esophageal reflux as trigger in asthma. Dis Chest 1976; 49: 464-466.

3- Kjellen C: Esophageal dysfunction and bronchial asthma. Liiikoping University medical dissertations. Ed Grafiska, Vimmerby 1981; 111: 7-30.

4- Perrin-Fayolle M, Bel A, Kofman J, Harf R, Montagnon B, Pacheco Y, et al: Asthme et reflux gastro-oesophagien: $\mathrm{r} \#\{233\}$ sultats d'une enqu\# $\{234\}$ teportant sur 150 cas. Poumon Coeur 1980; 36: 225-230

5- Goodall MJR, Earns JE, Cooper DN, Bernstein A, Temple JG: Relationship between asthma and gastroesophageal refiux. Thomx 1981; 36: 116-121.

6- Kjellen C, Tibbling L, Wranne B: Effect of conservation treatment of esophageal dysfunction on bronchial asthma. Ear $J$ Respir Dis 1981; 62: 190-197.

7- Drug VL, Cobzeanu D, Papaghuic C, et al: Gastrooesophageal reflux involvement in ENT disorders. Rev Med Chir Soc Med Nat Iasi 2005; 109: 220-222.

8- Poelmans J, Feenstra L, Tack J: Detrminants of long-term outcome of patients with reflux related ear, nose, and throat symptoms. Dig Dis Sci 2006; 51: 282-288.

9- Sontag SJ, O'Connel S, Khandelwal $\mathrm{S}$, et al: Most asthmatics have gastrooesophageal reflux with or without bronchodilator therapy. Gastroenterology 1990; 99: 613-620.

10-Ghillebert G, Janssens J, Vantrappen G, Nevens F, Piessens J: Ambulatory 24hour intraoesophageal $\mathrm{pH}$ and pressure recordings vs. provocation tests in the diagnosis of chest pain of oesophageal origin. Gut 1990; 31: 738-744.

11-Vincent D, Cohn-Jonathan AM, Leport $\mathrm{J}$, et al: Gastro-oesophageal reflux prevalence and relationship with bronchial reactivity in asthma. Eur Respir $J$ 1997; 10: 2255-2259.

12-Balson BM, Kravitz EKS, McGeady SJ: Diagnosis and treatment of gastroesophageal reflux in children and adolescents with severe asthma. Ann Allergy Asthma Immunol 1998; 81: 159-164.

13-Brent P Riscili, MD, et al: Treating silent reflux disease does not improve poorly controlled asthma. Cleveland clinic Journal of medicine 2010; 77(3).

14-Koufman JA, Aviv JE, Casiano RR, Shaw GY: Laryngopharyngeal reflux: Position statement of the committee on speech, voice, and swallowing disorders of the American Academy of OtolaryngologyHead and Neck Surgery. Otolaryngol Head Neck Surg 2002; 12 (7): 32-35.

15-DiMango E, Holbrook JT, et al: Effects of asymptomatic proximal and distal 
gastroesophageal reflux on asthma severity. American Journal of Respiratory and Critical Care Medicine 2009; 180.

16-Novitsky YW, Zawacki JK, Irwin RS, et al: Chronic cough due to gastroesophageal reflux disease efficacy of antireflux surgery. Surg Endosc 2002; 16: 567-571.

17-DeMeester TR, Bonovina L, Albertucci M: Nissen fundoplication for gastrooesophageal reflux disease. Evaluation of primary repair in 100 consecutive patients. Ann Surg 1986; 204: 9-20.

18-Dassinger MS: Laparoscopic fundoplication: 5-year followup. Am Surg 2004; 70: 691-694.

19-Deron J Tessier, MD: Medical, surgical, and endoscopic management of gastroesophageal reflux disease. The Permanente Journal 2009; 13(1).

20-Choy D, Leung R: Gastro-oesophageal reflux disease and asthma. Respirology 1997; 2: 163-168.

21-Zerbib F, Guisset O, Lamouliatte $\mathrm{H}$, Quinton A, Galmiche JP, Tunon- De-Lara JM: Effects of bronchial obstruction on lower esophageal sphincter motility and gastroesophageal reflux in patients with asthma. Am J Respir Crit Care Med 2002; 166: 1206-1211.

22-Lacy BE, Mathis C, DesBiens J, Liu MC:
The effects of nebulized albuterol on esophageal function in asthmatic patients. Dig Dis Sci 2008; 53: 2627-2633.

23-Mays EE: Intrinsic asthma in adults: Association with gastroesophageal reflux. JAMA 1976; 236: 2626-2628.

24-Ducolone A, Vanbevenne A, Jouin H, Grob JC, Coumaros D, Meyer C, et al: Gastroesophageal reflux in patients with asthma and chronic bronchitis. Am Rev Resp Dis 1987; 135: 327-332.

25-Mansfield LE, Hameister HH, Spaulding HS, Smith NJ, Glab N: The role of the vagus nerve in airway narrowing caused by intnaesophageal hydrochloric acid provocation and esophageal distention. Ann Allergy 1981; 47: 431-434.

26-Andersen LI, Shmidt A, Bundgaard A: Pulmonary function and acid application in the esophagus. Chest 1986; 3: 358-363.

27-Bernstein LM, Baker LA: A clinical test for esophagitis. Gastroenterology 1958; 34: 760-781.

28-Herve P, Denjean A, Jian R, Simonneau C, Duroux P: Esophageal perfusion of acid increases the bronchomotor response to methacholine and to isocapnic hyperventilation in asthmatic subjects. Am Rev Respir Dis 1986; 134: 986-989. 